OPEN ACCESS

Edited by:

Huilian Ma,

The University of Utah, United States

Reviewed by:

Yohannes Yihdego,

La Trobe University, Australia

William Paul Johnson,

The University of Utah, United States

*Correspondence:

Ofer Dahan

odahan@bgu.ac.il

Specialty section:

This article was submitted to

Water and Critical Zone,

a section of the journal

Frontiers in Water

Received: 27 August 2020 Accepted: 16 November 2020

Published: 14 December 2020

Citation:

Dahan O (2020) Vadose Zone Monitoring as a Key to Groundwater Protection. Front. Water 2:599569.

doi: 10.3389/frwa.2020.599569

\section{Vadose Zone Monitoring as a Key to Groundwater Protection}

\author{
Ofer Dahan*
}

Zuckerberg Institute for Water Research (ZIWR), The Blaustein Institutes for Desert Research, Ben-Gurion University of the Negev, Beersheba, Israel

Currently, monitoring programs designed for groundwater protection are mainly based on information from observation wells. This, however, creates a paradox, since identification of pollution in well water is clear evidence that the groundwater is already polluted. The poor state of contaminated aquifers all over the world, and the inability, in practice, to fully remediate contaminated aquifers suggest that groundwater monitoring alone has failed to provide the vital information required to prevent groundwater pollution. That said, groundwater pollution initiates on the land surface, and the contaminants have to traverse the unsaturated zone, long before reaching the water table. Therefore, monitoring programs that can provide real-time information on the hydraulic and chemical state of the unsaturated zone are essential for achieving early warnings of pollution potential and providing imperative protection from pollution hazards. Currently, most of the commercially available monitoring technologies are rather limited in their capability to provide early alerts of pollution processes taking place deep in the unsaturated zone, above the water table. Accordingly, monitoring technologies for the unsaturated zone have to be engineered as "off-the-shelf" commercial products, made available for application by practitioners in all fields of hydrology. From scientific and technological points of view, such ambitions are not out of reach. Yet they require an urgent call for a revolutionary shift in monitoring focus, from the groundwater itself to the unsaturated zone above it.

Keywords: groundwater pollution, unsaturated zone, vadose zone monitoring, early warning on pollution events, contaminant transport

\section{INTRODUCTION}

\section{The Paradox}

Public and political awareness of pollution's impact on the deterioration of groundwater resources and the consequent risk to public health has led to active protection of groundwater resources from human-made pollution (EPA, 2004; EUR-LEX, 2006; Environmental Agency, 2018). In recent years, substantial regulatory actions, aimed at preventing groundwater pollution through reducing pollutant load from point and non-point sources, have been taken all over the world (OECD, 2006; Hu, 2015; EPA, 2017; G20, 2017; California Water Board, 2020). Nevertheless, any program for groundwater protection requires efficient monitoring schemes that can provide reliable information on the hydrological and chemical state of the subsurface. Today, most groundwater pollution monitoring programs are based on information that is obtained from the groundwater itself. This information is usually retrieved from wells penetrating the saturated section of the subsurface. This type of monitoring procedure is well-grounded in both scientific 
studies and legislative acts that enforce groundwater monitoring programs wherever groundwater is endangered by potential pollution sources (U.S. EPA, 2006; European Commission, 2012; Boulding and Ginn, 2016; Yihdego et al., 2017). Accordingly, the entire path and fate of pollutants transported from their source on the land surface, through the unsaturated zone (also known as the vadose zone) to the aquifer below, are evaluated from the chemical and hydraulic characteristics of the groundwater under the water table (Figure 1).

Monitoring the groundwater's hydraulic and chemical state for the sake of pollution protection creates a paradox. Obviously, contaminant identification in the groundwater means that these contaminants have already crossed the entire unsaturated zone and accumulated in the aquifer water at detectable levels. Slow flow velocities, as well as dispersion and dilution processes taking place in the aquifers, often result in a lag time of years to decades between the initiation of a pollution event near the land surface to its identification in well water. As a result, a large contaminant mass accumulates in the subsurface, creating a contamination plume that spreads vertically and laterally in the underlying aquifer, long before it is discovered in well water. Pollution identification in well water often reveals only the edges of a much larger pollution plume, due to natural hydrodynamic dispersion processes, which reduce concentrations at the plume edges. The long lag time between initiations of unnoticed pollution events and their final detection in well water may be one of the main reasons for continuous groundwater quality degradation (Gal et al., 2009; Sagi-Ben Moshe et al., 2010; Ascott et al., 2017). Unfortunately, the history of groundwater monitoring emphasizes that well data mostly provide late alerts of advanced groundwater deterioration.

\section{Lost Battle}

Groundwater pollution has a huge economic impact on both public and private sectors. In addition to the direct loss of water resources, polluted properties are often declared as brownfields, with severe restrictions on usage and development (EPA, 2017, 2019; European Commission, 2019). Such restrictions are often enforced until cleanup and remediation programs are implemented and proven to be effective and safe (Yihdego and Al-Weshah, 2018). It is difficult to accurately estimate the economic damage related to brownfields and the capital investment required for their redevelopment and reuse. However, it appears that the global direct and indirect costs to both government and private sectors exceed hundreds of billions of dollars (EUA, 2019; EPA, 2020). Today, various biological, chemical, and physical remediation methods are available and implemented in contaminated sites worldwide. Nevertheless, it is, to the best of our knowledge, a fact that despite the enormous scientific efforts and capital investment, no polluted aquifer has ever been fully remediated to drinking water standards (European Commission, 2012). Accordingly, it may be stated that a polluted aquifer is, for all intents and purposes, a dead aquifer. Moreover, a polluted aquifer will continue to drain economic resources in attempts to prevent contaminant spread.

\section{Unsaturated Zone: Venue for Pollution or Key to Groundwater Protection?}

Contaminant identification in well water is clear evidence that the pollutants have already accumulated in the aquifer (Figure 1). Since groundwater remediation technologies are still incapable of saving the aquifer from its contaminated fate, it is obvious that early warnings of pollution potential should be received long before contaminants have crossed the water table. Accordingly, efficient monitoring programs that aim to protect groundwater from pollution need to be able to provide realtime information on the quality of the percolating water in the unsaturated zone above the water table. This, however, requires a revolutionary shift in monitoring focus from the groundwater to the unsaturated zone.

Groundwater pollution is attributed to a very large array of point and non-point contamination sources, such as surface and subsurface storage facilities for hazardous materials, intensive agriculture, industrial production zones, landfills, etc. Nevertheless, all of these potential pollution sources are either on the land surface or near it, above the unsaturated zone, which makes their location, in most cases, known and visible. Yet, the facts that flow trajectories in the unsaturated zone are mostly vertical and that contaminant spreading is limited to vertical drainage, from their original sources down toward the water table, imply that the pollution processes may be tracked in advance if data on flow and transport in the unsaturated zone become available. As opposed to the vertical flow trajectory in the unsaturated zone, flow trajectory in the aquifer is mostly horizontal. Moreover, in the aquifer, the flow trajectories may change frequently, following seasonal hydrological cycles and alteration of the groundwater abstraction regime. All of these factors result in extensive lateral dispersion and spreading of the contamination plume over a large area. While the impacted polluted area in the unsaturated zone is restricted to the polluted surface area, with only minor lateral migration, the dispersion and dilution processes in the aquifer water are much larger. This dramatically reduces the ability to achieve early identification of groundwater pollution. In addition, contaminant spreading in the aquifer often results in very low concentrations on the edges of the contaminant plume, while contaminant concentration in the unsaturated zone often preserves the source's high concentrations, with only minimal dilution. Accordingly, pollution identification capability in the unsaturated zone is higher compare to the saturated zone ( $\mathrm{Gal}$ et al., 2009; Dahan et al., 2014; Turkeltaub et al., 2016; Avishai et al., 2017; Moshkovich et al., 2017).

\section{State of the Art vs. State of the Requirements}

The notion that effective monitoring of the unsaturated zone is essential for groundwater pollution protection is based on the following facts: (1) most pollution processes initiate at known potential pollution sources near the land surface above the unsaturated zone; (2) contaminants migrate vertically through the unsaturated zone beneath the pollution sources before reaching the groundwater where they start spreading laterally; 


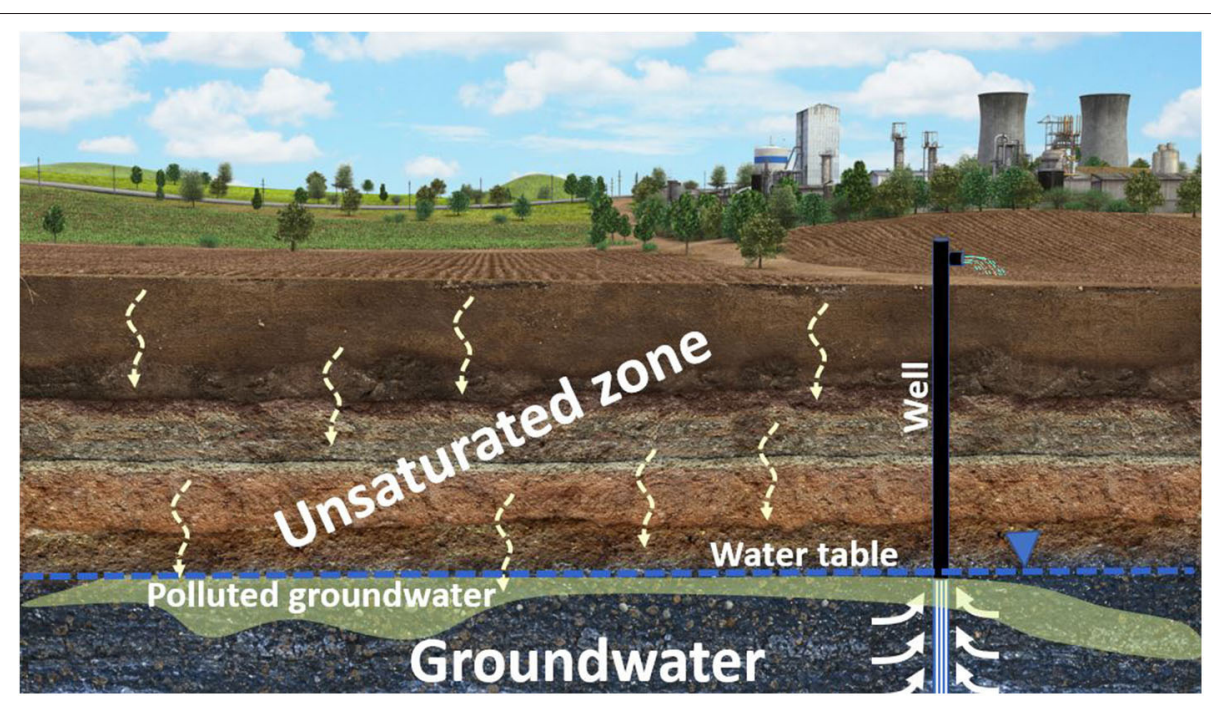

FIGURE 1 | Illustration of the subsurface hydrological domains. The figure emphasizes the link between water infiltration and contaminant transport through the unsaturated zone to the groundwater below.

(3) dilution and dispersion processes in the aquifer water delay contaminant detection in groundwater wells; (4) identification of pollutants in well water is a late alert for large contaminant masses accumulating in the aquifers; and (5) groundwater remediation technology is still incapable of comprehensively cleaning the aquifer to drinking water standards. Accordingly, an efficient monitoring system that aims to provide early warnings of pollution potential must be able to perform the following: (1) provide continuous in-situ measurements in the unsaturated zone, (2) enable high resolution hydraulic information that can be used for real-time assessment of percolation velocities and water fluxes, and (3) enable frequent sampling of vadose zone pore water for analysis of water chemical composition. Such monitoring equipment should be designed for longterm, continuous measurements and operated as permanent monitoring stations, as is typically done in weather stations or groundwater monitoring networks.

The current state of monitoring technologies for the unsaturated zone may be expressed by comparing off-the-shelf, commercially available instruments for groundwater with those available for the unsaturated zone. Such a comparison may be accomplished through a quick tour through the exhibition halls of large hydrology and geophysics conferences, as well as in other advertisement platforms of professional journals. Here, there is a staggering difference in the abundance of companies that supply monitoring technologies and services for the saturated domain, compared with those for the unsaturated domain. While many companies offer a wide selection of probes for continuous monitoring of groundwater's hydraulic and chemical properties, only a few companies provide monitoring equipment and services for the unsaturated domain. Most of these are soilrelated moisture sensors, tensiometers, and suction lysimeters that are designed for shallow soils or the root zone. However, technologies for real-time continuous monitoring of flow and transport in deep sections of the unsaturated zone can hardly be found. The absence of commercially available technologies for the deep unsaturated zone may be attributed to a lack of commercial interest in developing products for a market that seems too small to invest in development. On the other hand, it may also be claimed that the abundance of monitoring technologies for the saturated domain drives practitioners and scientists to focus on the location where this plethora of available tools provides instant results with substantial data, which can be analyzed and presented to relevant clients. As a result, the interest of commercial companies in developing monitoring tools for the unsaturated zone remains limited, in spite of the wellknown and critical role of the unsaturated zone in preventing groundwater pollution.

\section{Challenges}

\section{Sampling Water From Unsaturated Sediments}

Monitoring of contaminant migration in the unsaturated zone imposes major technical challenges. In unsaturated conditions, water is retained under capillary forces. Thus, the water is held under tension and sub-atmospheric pressure conditions (Jury and Fluhler, 1992). The water pressure is negatively correlated to the sediment saturation degree with respect to the sediment's physical structure and grain size distribution (Simunek et al., 2003; Jarvis, 2007). The sediment water content and related pressure are subjected to frequent variations, which are dictated by the erratic nature of surface water (e.g., rain, irrigation, floods, etc.) that percolates into the unsaturated zone. Therefore, water sampling for chemical analysis and identification of contaminant migration in the unsaturated zone requires a technical mechanism that can overcome the pore water's capillary forces and collect enough liquid that can be used for chemical analysis. One common method of sampling soil pore water is by applying porous interfaces, also known as ceramic cups or suction lysimeters (Stephens, 1996). These porous interfaces need 
to have a very small pore size with high air entry pressure ( $>1$ bar) in order to overcome the sediment water tension.

Several physical obstacles exist in using porous interfaces to sample pore water from the unsaturated zone. Under the low water content that follows dry periods, the sediment water tension increases, and the capability to sample water is reduced. Moreover, since the water potential in the unsaturated zone is low, the water volume that can be sampled may also be very low. Nevertheless, current lab requirements for most analyses can be as low as a few ml. In addition, water is sampled through a porous interface, which practically means that only dissolved contaminants can be sampled since particulate material is filtered out.

\section{Common Methods for Vadose Zone Characterization}

One of the most practiced methodology in vadose zone studies is based on sediment sampling. Sediment samples, which can be obtained through a wide range of drilling and sampling techniques, provide depth distribution profiles of the unsaturated zone's chemical, isotopic, hydraulic and physical characteristics. This information is then used to set both the conceptual and numerical models for flow and transport in the unsaturated zone. Though profiles based on sediment samples are fundamental and used in most studies related to the unsaturated zone, they have a very limited capability of providing the information that is required to protect groundwater from pollution hazards. A sediment sample provides a snapshot in time on the sediment with only limited information on the dynamics of water flow and contaminant transport. Drilling for the sake of sediment sampling is usually done in a time resolution of years or, in rare cases, months, through soil characterization surveys or routine soil sampling in agriculture. However, depicting the dynamics of water infiltration from variations in the vadose zone's hydraulic and chemical properties requires a high time resolution of days to months (Rimon et al., 2007; Turkeltaub et al., 2014, 2015a). Moreover, recent studies show that the chemical composition of sediment extracts do not accurately represent the mobile water phase, even in homogeneous domains, such as sand formations (Rimon et al., 2011a; Kapetas et al., 2014). In addition, sediment sampling is usually considered only after pollution has already been found as part of site characterization efforts and not as a pollution prevention policy. Therefore, sediment sampling can hardly be considered as a monitoring means for groundwater protection from pollution.

Continuous monitoring of the soil's hydraulic and chemical properties is well-developed in soil studies, mainly in the agricultural sector (Dabach et al., 2015; Farsad et al., 2019; Kassaye et al., 2020). A large selection of water content sensors, tensiometers, and suction lysimeters are available. Yet, most of these products are designed for implementation in shallow soils. Although several studies have demonstrated the application of water content sensors and suction lysimeters in the deep vadose zone, they have hardly ever been used successfully for longterm monitoring of pollutant transport in deep unsaturated zones (Baram et al., 2016).

Gas sampling in the unsaturated zone is relatively simple and does not involve much technological complexity (Schloemer et al., 2013; Höhener and Ponsin, 2014). Therefore, it is commonly used to monitor contamination processes associated with volatile compounds (Bouchard et al., 2008; Rivett et al., 2011). Although the presence of volatile compounds in the unsaturated zone's gas phase is considered a direct indicator for liquid non-aqueous phase liquid (NAPL) pollution, such as hydrocarbons, it is very limited in its ability to depict the transport processes of liquid pollution. While gravitational forces dictate the downwards migration of the polluted liquid across the unsaturated zone, the gas phase is subject to significant lateral diffusion and dispersion (Moshkovich et al., 2017). Daily variation of atmospheric pressure results in significant transport of gases in a mechanism called barometric pump (Neeper, 2001; Rimon et al., 2011b). Under paved/sealed surfaces, such as gas station parking lots or buildings, the barometric pump is also responsible for significant lateral dispersion (Ronen et al., 2010). All these reduce the capability to use information from soil gas to assess real-time contaminant migration in the subsurface.

Geophysical methods, such as ground penetrating radar (GPR) and electric resistivity tomography (ERT), enable detailed descriptions of the subsurface's geological structure through the dielectric and electric resistivity field of its sediment (Davis and Annan, 1989; Samouëlian et al., 2005; Haaken et al., 2016; Liu et al., 2016). Both the sediment's dielectric and resistivity properties are strongly impacted by the its water content and chemical composition (Orlando, 2013; Vera et al., 2016). As such, infiltration events that result in a significant change in the vadose zone water content or salinity may be detected and visualized in a $3 \mathrm{D}$ representation of the water and salinity distribution in the subsurface (Hayley et al., 2009; Brindt et al., 2019). Although the potential for real-time monitoring of contamination processes with geophysical tools is promising (Wang et al., 2015; Comegna et al., 2019), the current state-of-the-art is not efficient enough to identify the transport of pollutants in concentrations that do not significantly alter the medium's electrical conductivity or dielectric properties.

Flow and transport models for the unsaturated zone, such as HYDRUS (Simunek and van Genuchten, 2008), IWAN (Krause et al., 2007), and MACRO (Jovanovic et al., 2008), are commonly used for site characterization and assessment of aquifer vulnerability. Improved capabilities, user friendliness, and robustness make numerical models some of the strongest tools in vadose zone hydrology. Nevertheless, as robust and effective as they can be, models need continuous hard data from independent observations of the unsaturated zone's hydraulic and chemical state. Real-time transient data, such as temporal variations in the profile water content, water pressure, chemical composition, and pollutant concentration in the vadose zone pore water, are essential for exploiting the models' full strength for groundwater protection from pollution. Currently, such information is mostly limited to the boundaries and hardly ever extends to the deep section of the unsaturated zone.

\section{Urgent Call}

The notion that groundwater pollution initiates as transport in the unsaturated zone, and the fact that common vadose 
zone methodologies have only limited ability to provide realtime alerts for pollution processes should push the research community to issue a clarion call to develop monitoring technologies for the unsaturated zone. Such monitoring technologies should be developed and engineered into commercial products that are readily available for application by practitioners in all fields of vadose zone hydrology, including: agriculture, landfill management, remediation of contaminated sites, groundwater protection from point and non-point source pollution, characterization of the pollution potential of accidental contaminant spills, etc. From the scientific and technological points of view, such ambitions are not out of reach. Yet, they require massive scientific and economic investment by the vadose zone research community in order to achieve significant progress in the field of unsaturated zone hydrology.

\section{Insights From Direct Monitoring of the Unsaturated Zone}

The need for real-time information on the quality of percolating water in the unsaturated zone led to the development of the VMS. The VMS is designed to provide continuous in-situ measurements of the unsaturated zone's hydraulic and chemical properties, from the land surface to the water table. The monitoring system is composed of flexible sleeves made of a thin liner, hosting a set of monitoring units, which are distributed along its length. The monitoring units include flexible time domain reflectometry sensors (FTDR) for continuous tracking of variations in sediment water content in the deep unsaturated zone (Dahan et al., 2007, 2008; Rimon et al., 2007), and vadose zone sampling ports (VSPs), which are designed for frequent sampling of sediment pore water (Dahan et al., 2009; Turkeltaub et al., 2014). The physical mechanism that allows the VSP to sample the vadose zone pore water is based on creating hydraulic continuity between the sediment pore water and a sampling cell. Similar to standard tensiometers and suction cups, the hydraulic continuity is achieved via a fine porous medium. Yet, the VSP's flexible structure and large surface area makes it very efficient in water sampling, even under very low sediment water potential and at great depths exceeding tens of meters. The VMS is installed in uncased small-diameter, slanted boreholes. In the borehole, the monitoring units are aligned along the upper side wall of the borehole annulus, facing the undisturbed sediment column, which extends from the probe location in the borehole to the land surface, thus facing an undisturbed sediment profile. Immediately after insertion of the sleeve into the borehole, it is filled with a non-shrinking cement grout to ensure the monitoring units' contact with the borehole walls, to seal its void, and to reconstruct the lithostatic pressure in the surrounding sediment.

The potential for in-situ monitoring of the unsaturated zone has been demonstrated through several studies where the VMS was used to measure flow velocities, solute transport, and chemical transformation of contaminants across the unsaturated zone. It has been implemented in a variety of studies on water flow and contaminant transport including: (a) rainwater infiltration and groundwater recharge (Rimon et al., 2007, 2011a,b), (b) floodwater infiltration from stream channels and reservoirs (Shani, 2006; Dahan et al., 2007, 2008, 2009), (c) impact of agricultural practices on groundwater quality (Baram et al., 2012; Dahan et al., 2014; Turkeltaub et al., 2015b, 2016; Weissman et al., 2020), (d) leachate generation and migration in landfills (Aharoni et al., 2017, 2020), and (e) interactive remediation of contaminated sites (Dahan et al., 2017; Moshkovich et al., 2017; Levakov et al., 2019). Scientific and environmental implications from a number of these studies are presented here to demonstrate the capability to continuously monitor water flow and contaminant migration in the unsaturated zone.

\section{Floodwater Infiltration}

A study on floodwater percolation and groundwater recharge from ephemeral stream channels was carried out using vadose zone monitoring systems (Dahan et al., 2007, 2008; Benito et al., 2010). Continuous data on the variation in the vadose zone water content during flood events, collected over a period of several years, enabled the direct calculation of floodwater infiltration fluxes and groundwater recharge rates with respect to the flood characteristics. Measured recharge values from the monitoring station were then used to calibrate regional flood routing models for the entire reach (Morin et al., 2009). In addition, the dynamics of water flow and contaminant transport in the unsaturated zone was first presented through a multitracer infiltration experiment in an alluvial formation underlying a stream channel (Dahan et al., 2009). Transient data on the variation of water content, along with tracer breakthrough at multiple depths, enabled direct calculation of water percolation velocities and contaminant migration fluxes through natural undisturbed flooding conditions.

\section{Rainwater Infiltration}

A vadose zone monitoring station that was installed in a sand dune area enabled long-term continuous measurement of rainwater percolation across a 20-m-thick vadose zone. Continuous data on the temporal variations in the water content, along with variations in pore water chemical composition, were collected for more than 10 years (since 2003). The long-term continuous data from the unsaturated zone enabled, for the first time, an estimate of groundwater recharge on the basis of direct hydraulic and chemical information from the entire unsaturated zone (Rimon et al., 2007, 2011a,b). Moreover, information on the unsaturated zone's dynamic response to the rain pattern was used to assess the impact of potential climate changes on groundwater recharge (Turkeltaub et al., 2014, 2015a).

\section{Agricultural Impact on Groundwater Quality}

Preserving groundwater quality under intensive agricultural fields is a special challenge. On one hand, increasing agricultural productivity is an important goal for achieving food security. On the other hand, maintaining the productivity of intensive agriculture often involves excessive use of agricultural inputs, such as fertilizers and pesticides. Unfortunately, intensive agricultural regimes often result in deterioration of groundwater quality and elevated concentrations of nitrate in many aquifers 
all over the world (Ascott et al., 2017). Regulations that limit fertilizer application have been enacted in many countries, in an attempt to reduce nitrate pollution in aquifers (Macintosh, 2018; California Water Board, 2020). Yet, limiting the total nitrogen application does not necessarily lead to the expected reduction in nitrate pollution since nitrate leaching is dependent on fertilizer application regimes rather than the total amount (Dahan et al., 2014). Therefore, maintaining the delicate balance between agricultural productivity and groundwater quality can only be achieved through continuous measurements of the chemical composition of the water migrating from the root zone through to the deep unsaturated zone. Information on variation in water chemical composition below the root zone will enable fertilizer application optimization, with respect to both productivity and quality of the water leaching down from the root zone. For example, vadose zone monitoring stations, which were installed under several representative agricultural setups, including greenhouses, orchards, open field crops, and dairy farms, enabled direct assessment of the agricultural regimes' impact on recharge water quality. Continuous information on the chemical and isotopic composition of pore water from the unsaturated zone of these agricultural fields was collected for over 10 years. The data enabled identification of pollution processes in the vadose zone, long before groundwater pollution became evident. It enabled the linking of specific agricultural regimes to enhanced pollution processes (Dahan et al., 2014; Turkeltaub et al., 2015b), the calibration of transport models to long-term transient data from the vadose zone (Turkeltaub et al., 2014, 2016), the identification of the mechanism controlling water and contaminant infiltration through clay sediments underlying dairy farms (Baram et al., 2012, 2013, 2014), and the acquisition of explicit information on the link between irrigation water salinity and increased nitrate transport from the root zone down to the groundwater (Weissman et al., 2020).

\section{Landfill Leachates' Impact on Groundwater}

Landfill leachates are known to have severe impacts on groundwater quality. The waste may generate polluted leachates many years after a landfill is closed. Any landfill restoration requires a proper understanding of the mechanisms controlling leachate generation and migration across the waste and in the underlying unsaturated zone. Vadose zone monitoring stations that were established in landfills provided long-term (8 years) continuous measurement of leachate percolation and chemical transformation in the waste body and underlying unsaturated zone. It enabled a detailed characterization of the relationship between the rain pattern, the landfill's morphological characteristics, and the groundwater pollution potential, as well as of the necessary actions for efficient site reclamation (Aharoni et al., 2017, 2020).

\section{Optimization of Bioremediation Strategies}

In-situ bioremediation of a contaminated unsaturated zone depends mainly on the ability to control the hydrological, physical, and chemical conditions in the subsurface. Application of vadose zone monitoring technology during a remediation operation enables optimizing the remediation strategy on the basis of real-time data on the unsaturated zone's chemical composition, saturation degree, and flow characteristics (Avishai et al., 2017; Dahan et al., 2017; Moshkovich et al., 2017; Levakov et al., 2019). Direct information from the unsaturated zone was used for real-time adjustment of water application cycles, nutrient augmentation, and supply of electron donors/acceptors to the treated soil. Continuous adjustment of the soil's hydraulic, chemical, and physical properties enables the improvement of biodegradation conditions and the minimization of groundwater pollution.

\section{Scientific Implications}

In addition to the direct information on the link between groundwater pollution potential and specific land use regimes, measurements of the dynamic processes taking place in the unsaturated zone enabled the identification of important physical mechanisms that control flow and transport in the unsaturated zone.

\section{Saturation Degree Under Flooded Conditions}

Floodwater infiltration in natural formations was found to take place in relatively low water content that never reaches the saturation degree (Dahan et al., 2007, 2008; Amiaz et al., 2011). The unsaturated conditions are maintained even very close to the flooded surface, regardless of the floodwater head, flood duration period, or sedimentological characteristics. Finally, saturation is achieved only upon the water table rising upward into the unsaturated zone. It has been shown that percolation fluxes are relatively constant, regardless of the floodwater head. This phenomenon has a significant impact on the modeling of flood water infiltration. Apparently, infiltration models under surface saturated conditions often result in a saturated wetting front that progresses down the unsaturated zone to the water table. However, direct observation from the unsaturated zone showed that the infiltration process, even in sandy homogeneous formations, takes place under unsaturated conditions, while saturation is achieved only by the water table's rise into the unsaturated zone, once the groundwater recharge process initiates (Dahan et al., 2008).

\section{Chemical Equilibrium of Percolating Water}

Long-term continuous measurements of the pore water's chemical composition with respect to variations in water content, temperature, and pressure, across a deep sandy unsaturated zone, revealed that a major portion of the solute potential is not in equilibrium with the percolating water (Amiaz et al., 2011; Rimon et al., 2011a). This phenomenon was observed in the least expected conditions, which included well-sorted homogeneous sand of natural dunes, which are subjected to high annual rain amounts or even flooded conditions. The direct outcome is that gravitational percolation of water in the unsaturated zone is incapable of complete leaching of the sediment solute potential. It has been found that full leaching of the soluble solutes may be achieved only through saturation, which can occur only upon the rise of the water table. Obviously, this phenomenon has a dramatic impact on transport models, which often require different chemical equilibrium levels of the mobile flowing water 
with the solute potential, especially in a "so-called" homogeneous medium, such as well-sorted sand.

\section{Infiltration Through Clay Formations}

Heavy clay soils are regarded as less permeable due to their low saturated hydraulic conductivities, and are perceived as safe for the construction of unlined waste lagoons. Water percolation dynamics, as measured by vadose zone monitoring systems that were installed in a clay formation, showed a quick percolation pattern that contradicts this common knowledge of clay's hydraulic properties. Obviously, such quick infiltration cannot be analyzed through conventional physical models due to the inherently low hydraulic conductivity of clay formations (Baram et al., 2012). It has been proposed that desiccation crack networks that develop naturally in unsaturated clay formations remain open and serve as a preferential flow pathway year-round, even at high sediment water content. Moreover, the desiccation crack networks induce rapid infiltration of contaminated water to deep sections of the unsaturated zone, bypassing the sediment's biogeochemically active zone, and jeopardizing groundwater quality. This makes clay formations more vulnerable to pollution than other formations, such as sand, loess, and alluvium.

\section{Induced Salinization}

Five-year continuous measurements of the temporal variation in water content and chemical and isotopic composition in an unsaturated clay formation revealed subsurface evaporation processes that are induced by a desiccation crack aeration mechanism (Baram et al., 2013). The measurements provided evidence of deep subsurface evaporation and solute accumulation at depths reaching $3-4 \mathrm{~m}$ below ground level. Moreover, the desiccation crack network enhanced the downflushing of concentrated solutions from the evaporative zones following rain events, which contributed to salinization of the underlying aquifer.

\section{Enhanced Nitrate Transport and Irrigation Salinity}

Dynamics of solute transport in the unsaturated zone was measured using vadose zone monitoring systems under cultivated agricultural fields that were treated with variable levels of $\mathrm{N}$ fertilization and water salinity (Weissman et al., 2020). It was found that irrigating with higher salinity water $(350 \mathrm{mg} / \mathrm{l} \mathrm{Cl})$ resulted in the earlier arrival of wetting fronts to the deeper layers of the unsaturated zone and increased nitrate concentrations, relative to the lower salinity treatments (100 $\mathrm{mg} / \mathrm{l})$. Although both salinity concentrations are categorized as fresh water that can be used directly for agricultural irrigation, it seems that application of the higher salinity irrigation water results in increased levels of nitrate pollution to the groundwater, even when both treatments have the same nitrogen fertilization regime.

\section{DISCUSSION}

The unsaturated zone is known for the critical role it plays in controlling groundwater quality. It is the domain through which surface water infiltrates to recharge the aquifers. Yet, it is the domain through which contaminants are transported down from their original source on the land surface to the water table below. It is a biologically active domain, where natural or enhanced contaminant degradation takes place, especially in the top soil and the shallow sections of the unsaturated zone. It is a domain where the flow trajectories are mostly vertical, and pollutants travel directly down from their original sources through confined boundaries of the contaminated area on the land surface. It is a domain where contaminants exist at their highest original concentrations and can be detected long before they are diluted and dispersed laterally in the vast aquifer. Yet, it is unfortunate that to date, most of the scientific and legislative efforts to monitor, characterize, and protect groundwater from pollution hazards are, for all practical purposes, based on groundwater monitoring in wells. This is the case, despite the fact that the history of hydrological studies shows that no groundwater monitoring network has saved an aquifer from a polluted fate, simply since they only provide belated alerts on pollution that has already progressed in the aquifer body. Moreover, the staggering capital investment in the remediation of contaminated aquifers worldwide has not changed their status by restoring them to drinking water standards. Acknowledging the fact that a polluted aquifer is, in practical terms, a dead aquifer means that saving aquifers from pollution has to include monitoring technologies that can provide early warnings of pollution potential. As shown here, this goal is achievable, as the unsaturated zone contains all the necessary information on contamination potential. Yet, it requires major dedicated scientific and legislative efforts to develop efficient monitoring tools that are capable of providing real-time, continuous information on water flow and contaminant transport in the unsaturated zone. If protecting groundwater from pollution hazards is the ultimate goal, then these monitoring tools should be developed for commercial applications, and made accessible to hydrologists in environmental consulting companies, and not just to highly skilled scientists.

\section{AUTHOR'S NOTE}

The manuscript "Vadose-zone Monitoring as a Key to Groundwater Protection" is the outcome of many years of continuous research in the field of water flow and contaminant transport in the unsaturated zone. We have studied this broad and complex subject in a very wide range of hydrogeological setups, as well as under various natural and anthropogenic conditions, including: (a) rainwater infiltration and groundwater recharge (b) floodwater infiltration from stream channels and reservoirs, (c) impact of various agricultural practices on groundwater quality, (d) leachates generation and migration in landfills, and (e) interactive remediation of contaminated sites. From all scientific implications there is one conclusion that rose above all. Saving groundwater from pollution hazard requires massive shift in monitoring effort from groundwater into the unsaturated zone. This is the 
domain through which contaminates has to migrate through prior to accumulation in groundwater. Therefore, efficient monitoring of the unsaturated zone is critical for prevention of groundwater pollution.

\section{REFERENCES}

Aharoni, I., Siebner, H., and Dahan, O. (2017). Application of vadosezone monitoring system for real-time characterization of leachate percolation in and under a municipal landfill. Waste Manag. 67, 203-213. doi: 10.1016/j.wasman.2017.05.012

Aharoni, I., Siebner, H., Yogev, U., and Dahan, O. (2020). Holistic approach for evaluation of landfill leachate pollution potential-from the waste to the aquifer. Sci. Total Environ. 741:140367. doi: 10.1016/j.scitotenv.2020.140367

Amiaz, Y., Sorek, S., Enzel, Y., and Dahan, O. (2011). Solute transport in the vadose zone and groundwater during flash floods. Water Resour. Res. 47, 1-10. doi: 10.1029/2011WR010747

Ascott, M. J., Gooddy, D. C., Wang, L., Stuart, M. E., Lewis, M. A., Ward, R. S., et al. (2017). Global patterns of nitrate storage in the vadose zone. Nat. Commun. 8:1416. doi: 10.1038/s41467-017-01321-w

Avishai, L., Siebner, H., Dahan, O., and Ronen, Z. (2017). Using the natural biodegradation potential of shallow soils for in-situ remediation of deep vadose zone and groundwater. J. Hazard. Mater. 324, 398-405. doi: 10.1016/j.jhazmat.2016.11.003

Baram, S., Couvreur, V., Harter, T., Read, M., Brown, P. H., Hopmans, J. W., et al. (2016). Assessment of orchard $\mathrm{N}$ losses to groundwater with a vadose zone monitoring network. Agric. Water Manag. 172, 83-95. doi: 10.1016/j.agwat.2016.04.012

Baram, S., Kurtzman, D., and Dahan, O. (2012). Water percolation through a clayey vadose zone. J. Hydrol. 424-425. doi: 10.1016/j.jhydrol.2011.12.040

Baram, S., Kurtzman, D., Ronen, Z., Peeters, A., and Dahan, O. (2014). Assessing the impact of dairy waste lagoons on groundwater quality using a spatial analysis of vadose zone and groundwater information in a coastal phreatic aquifer. J. Environ. Manage. 132, 135-144. doi: 10.1016/j.jenvman.2013.11.008

Baram, S., Ronen, Z., Kurtzman, D., Külls, C., and Dahan, O. (2013). Desiccationcrack-induced salinization in deep clay sediment. Hydrol. Earth Syst. Sci. 17, 1533-1545. doi: 10.5194/hess-17-1533-2013

Benito, G., Rohde, R., Seely, M., Külls, C., Dahan, O., Enzel, Y., et al. (2010). Management of alluvial aquifers in two Southern African ephemeral rivers: implications for IWRM. Water Resour. Manag. 24, 641-667. doi: $10.1007 /$ s11269-009-9463-9

Bouchard, D., Hunkeler, D., Gaganis, P., Aravena, R., Höhener, P., Broholm, M. M., et al. (2008). Carbon isotope fractionation during diffusion and biodegradation of petroleum hydrocarbons in the unsaturated zone: field experiment at Vaerløse Airbase, Denmark, and modeling. Environ. Sci. Technol. 42, 596-601. doi: 10.1021/es070718f

Boulding, J. R., and Ginn, J. S. (2016). Practical Handbook of Soil, Vadose Zone, and Ground-Water Contamination. Boca Raton, FL: CRC Press. doi: 10.1201/9781420032147

Brindt, N., Rahav, M., and Wallach, R. (2019). ERT and salinity-a method to determine whether ERT-detected preferential pathways in brackish waterirrigated soils are water-induced or an artifact of salinity. J. Hydrol. 574, 35-45. doi: 10.1016/j.jhydrol.2019.04.029

California Water Board (2020). How do the Water Boards protect groundwater? Ca.gov. Available online at: https:/www.waterboards.ca.gov/water_issues/ programs/groundwater/protecting_gw.html (accessed November 29, 2020).

Comegna, A., Coppola, A., Dragonetti, G., and Sommella, A. (2019). A soil non-aqueous phase liquid (NAPL) flushing laboratory experiment based on measuring the dielectric properties of soil-organic mixtures via time domain reflectometry (TDR). Hydrol. Earth Syst. Sci. 23, 3593-3602. doi: 10.5194/hess-23-3593-2019

Dabach, S., Shani, U., and Lazarovitch, N. (2015). Optimal tensiometer placement for high-frequency subsurface drip irrigation management in heterogeneous soils. Agric. Water Manag. 152, 91-98. doi: 10.1016/j.agwat.2015.01.003

Dahan, O., Babad, A., Lazarovitch, N., Russak, E. E., and Kurtzman, D. (2014). Nitrate leaching from intensive organic farms to groundwater. Hydrol. Earth Syst. Sci. Discuss. 10, 9915-9941. doi: 10.5194/hessd-10-9915-2013

\section{AUTHOR CONTRIBUTIONS}

The author confirms being the sole contributor of this work and has approved it for publication.

Dahan, O., Katz, I., Avishai, L., and Ronen, Z. (2017). Transport and degradation of perchlorate in deep vadose zone: implications from direct observations during bioremediation treatment. Hydrol. Earth Syst. Sci. 21, 4011-4020. doi: 10.5194/hess-21-4011-2017

Dahan, O., Shani, Y., Enzel, Y., Yechieli, Y., and Yakirevich, A. (2007). Direct measurements of floodwater infiltration into shallow alluvial aquifers. J. Hydrol. 344, 157-170. doi: 10.1016/j.jhydrol.2007.06.033

Dahan, O., Talby, R., Yechieli, Y., Adar, E., Lazarovitch, N., and Enzel, Y. (2009). In situ monitoring of water percolation and solute transport using a vadose zone monitoring system. Vadose Zo. J. 8, 823-824. doi: 10.2136/vzj 2008.0134

Dahan, O., Tatarsky, B., Enzel, Y., Kulls, C., Seely, M., and Benito, G. (2008). Dynamics of flood water infiltration and ground water recharge in hyperarid desert. Ground Water 46, 450-461. doi: 10.1111/j.1745-6584.2007.00414.x

Davis, J. L., and Annan, A. P. (1989). Ground-penetrating radar for highresolution mapping of soil and rock stratigraphy. Geophys. Prospect. 37, 531-551. doi: 10.1111/j.1365-2478.1989.tb02221.x

Environmental Agency (2018). The Environment Agency's Approach to Groundwater Protectiontle. UK GOV. Available online at: https://www.gov. $\mathrm{uk} /$ government/publications/groundwater-protection-position-statements (accessed November 29, 2020).

EPA (2004). Handbook of Groundwater Protection and Cleanup Policies for RCRA Corrective Action for Facilities. United States Environmental Protection Agency. Available online at: https://www.epa.gov/sites/production/files/201702/documents/gwhb041404.pdf (accessed November 29, 2020).

EPA (2017). Brownfields. United States Environmental Protection Agency. Available online at: https://www.epa.gov/brownfields (accessed November 29, 2020).

EPA (2019). Federal Government's Program to Clean Up of the Nation's Uncontrolled Hazardous Waste Sites. Available online at: http://www.epa.gov/superfund (accessed November 29, 2020).

EPA (2020). Superfund Remedy Report. EPA. Available online at: https://www. epa.gov/sites/production/files/2020-07/documents/100002509.pdf (accessed November 29, 2020).

EUA (2019). Progress in Management of Contaminated Sites. European Environmental Agency. Available online at: https://www.eea. europa.eu/ data and maps/indicators/progress in management of contaminated sites/assessment (accessed November 29, 2020).

EUR-LEX (2006). Directive 2006/118/ec of the European Parliament on the Protection of Groundwater Against Pollution. Official Journal of European Union, L 372/19. Available online at: https://eur-lex.europa.eu/legal-content/ EN/TXT/?uri=uriserv:OJ.L_.2006.372.01.0019.01.ENGandtoc=OJ:L:2006:372: TOC (accessed November 29, 2020).

European Commission (2012). Groundwater as a Resource. EU Framework Directive. Available online at: https://ec.europa.eu/environment/water/waterframework/groundwater/resource.htm (accessed November 29, 2020).

European Commission (2019). Brownfield Redevelopment in the EU. European Commission. Available online at: https://ec.europa.eu/info/events/brownfieldredevelopment-eu-2019-apr-05_en (accessed November 29, 2020).

Farsad, A., Sadeghpour, A., Hashemi, M., Battaglia, M., and Herbert, S. J. (2019). A review on controlled vacuum lysimeter design for soil water sampling. Environ. Technol. Innov. 14:100355. doi: 10.1016/j.eti.2019.100355

G20 (2017). Towards Food and Water Security: Fostering Sustainability, Advancing Innovation. University of Toronto Library. Available online at: http://www.g20. utoronto.ca/2017/170122-agriculture-action-en.html (accessed November 29, 2020).

Gal, H., Weisbrod, N., Dahan, O., Ronen, Z., and Nativ, R. (2009). Perchlorate accumulation and migration in the deep vadose zone in a semiarid region. $J$. Hydrol. 378, 142-149. doi: 10.1016/j.jhydrol.2009.09.018

Haaken, K., Furman, A., Weisbrod, N., and Kemna, A. (2016). Time-lapse electrical imaging of water infiltration in the context of soil aquifer treatment. Vadose Zo. J. 15, 1-12. doi: 10.2136/vzj2016.04.0028 
Hayley, K., Bentley, L. R., and Gharibi, M. (2009). Time-lapse electrical resistivity monitoring of salt-affected soil and groundwater. Water Resour. Res. 45, 1-14. doi: 10.1029/2008WR007616

Höhener, P., and Ponsin, V. (2014). In situ vadose zone bioremediation. Curr. Opin. Biotechnol. 27, 1-7. doi: 10.1016/j.copbio.2013.08.018

Hu, F. (2015). Groundwater Under Pressure. CWR. Available online at: https:// www.chinawaterrisk.org/resources/analysis-reviews/groundwater-underpressure/ (accessed November 29, 2020).

Jarvis, N. J. (2007). A review of non-equilibrium water flow and solute transport in soil macropores: principles, controlling factors and consequences for water quality. Eur. J. Soil Sci. 58, 523-546. doi: 10.1111/j.1365-2389.2007.00915.x

Jovanovic, N. Z., Majola, K. A., Ginster, M., and Adams, S. (2008). Preferential flow modelling in the vadose zone using MACRO 5.0: cape flats sands and mpumalanga clays case studies (South Africa). WIT Trans. Ecol. Environ. 109, 373-382. doi: 10.2495/WM080391

Jury, W. A., and Fluhler, H. (1992). Transport of chemicals through soilmechanisms, models, and field applications. Adv. Agron. 47, 141-201. doi: 10.1016/S0065-2113(08)60490-3

Kapetas, L., Dror, I., and Berkowitz, B. (2014). Evidence of preferential path formation and path memory effect during successive infiltration and drainage cycles in uniform sand columns. J. Contam. Hydrol. 165, 1-10. doi: 10.1016/j.jconhyd.2014.06.016

Kassaye, K. T., Boulange, J., Lam, V. T., Saito, H., and Watanabe, H. (2020). Monitoring soil water content for decision supporting in agricultural water management based on critical threshold values adopted for andosol in the temperate monsoon climate. Agric. Water Manag. 229:105930. doi: 10.1016/j.agwat.2019.105930

Krause, S., Jacobs, J., and Bronstert, A. (2007). Modelling the impacts of land-use and drainage density on the water balance of a lowlandfloodplain landscape in northeast Germany. Ecol. Modell. 200, 475-492. doi: 10.1016/j.ecolmodel.2006.08.015

Levakov, I., Ronen, Z., and Dahan, O. (2019). Combined in-situ bioremediation treatment for perchlorate pollution in the vadose zone and groundwater. $J$. Hazard. Mater. 369, 439-447. doi: 10.1016/j.jhazmat.2019.02.014

Liu, X., Dong, X., and Leskovar, D. I. (2016). Ground penetrating radar for underground sensing in agriculture: a review. Int. Agrophys. 30, 533-543. doi: 10.1515/intag-2016-0010

Macintosh, E. (2018). Germany Faces Billions in Fines for Breaking EU Laws on Nitrate Pollution. EEB. Available online at: https://meta.eeb.org/2018/06/21/ germany-faces-billions-in-fines-for-breaking-eu-laws-on-nitrate-pollution/ (accessed November 29, 2020).

Morin, E., Grodek, T., Dahan, O., Benito, G., Kulls, C., Jacoby, Y., et al. (2009). Flood routing and alluvial aquifer recharge along the ephemeral arid Kuiseb river, Namibia. J. Hydrol. 368, 262-275. doi: 10.1016/j.jhydrol.2009. 02.015

Moshkovich, E., Ronen, Z., Gelman, F., and Dahan, O. (2017). In situ bioremediation of a gasoline-contaminated vadose zone: implications from direct observations. Vadose Zo. J. 17, 1-11. doi: 10.2136/vzj2017.08.0153

Neeper, D. A. (2001). A model of oscillatory transport in granular soils, with application to barometric pumping and earth tides. J. Contam. Hydrol. 48, 237-252. doi: 10.1016/S0169-7722(00)00181-9

OECD (2006). Better Policies to Improve the Environmental Performance of the Agriculture Sector. Available online at: https://www.oecd.org/agriculture/ topics/agriculture-and-the-environment (accessed November 29, 2020).

Orlando, L. (2013). GPR to constrain ERT data inversion in cavity searching: theoretical and practical applications in archeology. J. Appl. Geophys. 89, 35-47. doi: 10.1016/j.jappgeo.2012.11.006

Rimon, Y., Dahan, O., Nativ, R., and Geyer, S. (2007). Water percolation through the deep vadose zone and groundwater recharge: preliminary results based on a new vadose zone monitoring system. Water Resour. Res. 43, 1-12. doi: 10.1029/2006WR004855

Rimon, Y., Nativ, R., and Dahan, O. (2011a). Physical and chemical evidence for pore-scale dual-domain flow in the vadose zone. Vadose Zo. J. 10, 322-331. doi: 10.2136/vzj2009.0113

Rimon, Y., Nativ, R., and Dahan, O. (2011b). Vadose zone water pressure variation during infiltration events. Vadose Zo. J. 10, 1105-1112. doi: $10.2136 /$ vzj2010.0061

Rivett, M. O., Wealthall, G. P., Dearden, R. A., and McAlary, T. A. (2011). Review of unsaturated-zone transport and attenuation of volatile organic compound
(VOC) plumes leached from shallow source zones. J. Contam. Hydrol. 123, 130-156. doi: 10.1016/j.jconhyd.2010.12.013

Ronen, D., Lev-Wiener, H., Graber, E. R., Dahan, O., and Weisbrod, N. (2010). Simultaneous counter-flow of chlorinated volatile organic compounds across the saturated-unsaturated interface region of an aquifer. Water Res. 44, 2107-2112. doi: 10.1016/j.watres.2009.12.016

Sagi-Ben Moshe, S., Ronen, Z., Dahan, O., Bernstein, A., Weisbrod, N., Gelman, F., et al. (2010). Isotopic evidence and quantification assessment of in situ RDX biodegradation in the deep unsaturated zone. Soil Biol. Biochem. 42, 1253-1262. doi: 10.1016/j.soilbio.2010.04.011

Samouëlian, A., Cousin, I., Tabbagh, A., Bruand, A., and Richard, G. (2005). Electrical resistivity survey in soil science: a review. Soil Tillage Res. 83, 173-193. doi: 10.1016/j.still.2004.10.004

Schloemer, S., Furche, M., Dumke, I., Poggenburg, J., Bahr, A., Seeger, C., et al. (2013). A review of continuous soil gas monitoring related to CCS-technical advances and lessons learned. Appl. Geochem. 30, 148-160. doi: 10.1016/j.apgeochem.2012.08.002

Shani, Y. (2006). Floodwater Percolation and Groundwater Recharge in Wadi Arava, Israel. Beer Sheva.

Simunek, J., Jarvis, N. J., van Genuchten, M. T., and Gardenas, A. (2003). Review and comparison of models for describing non-equilibrium and preferential flow and transport in the vadose zone. J. Hydrol. 272, 14-35. doi: 10.1016/S0022-1694(02)00252-4

Simunek, J., and van Genuchten, M. T. (2008). Modeling nonequilibrium flow and transport processes using HYDRUS. Vadose Zo. J. 7, 782-797. doi: $10.2136 /$ vzj2007.0074

Stephens, D. B. (1996). Vadose Zone Hydrology. Lewis Publishers.

Turkeltaub, T., Dahan, O., and Kurtzman, D. (2014). Investigation of groundwater recharge under agricultural fields using transient deep vadose zone data. Vadose Zo. J. 13, 1-13. doi: 10.2136/vzj2013.10.0176

Turkeltaub, T., Kurtzman, D., Bel, G., and Dahan, O. (2015a). Examination of groundwater recharge with a calibrated/validated flow model of the deep vadose zone. J. Hydrol. 522, 618-627. doi: 10.1016/j.jhydrol.2015.01.026

Turkeltaub, T., Kurtzman, D., and Dahan, O. (2016). Real-time monitoring of nitrate transport in the deep vadose zone under a crop field-implications for groundwater protection. Hydrol. Earth Syst. Sci. 20, 3099-3108. doi: 10.5194/hess-20-3099-2016

Turkeltaub, T., Kurtzman, D., Russak, E. E., and Dahan, O. (2015b). Impact of switching crop type on water and solute fluxes in deep vadose zone. Water Resour. Res. 51, 9828-9842. doi: 10.1002/2015WR017612

U.S. EPA (2006). In Situ Treatment Technologies for Contaminated Soil. EPA. p. $15-20$.

Vera, N. F., De Beaujean, J., Hakoun, V., Caterina, D., Dahan, O., Vanclooster, M., et al. (2016). Tracer experiment in a brownfield using geophysics and a Vadose zone monitoring system. Vadose Z. J. 16, 1-15. doi: 10.2136/vzj2016.06.0051

Wang, T.-P., Chen, C.-C., Tong, L.-T., Chang, P.-Y., Chen, Y.-C., Dong, T.-H., et al. (2015). Applying FDEM, ERT and GPR at a site with soil contamination: a case study. J. Appl. Geophys. 121, 21-30. doi: 10.1016/j.jappgeo.2015.07.005

Weissman, G., Bel, G., Ben-Gal, A., Yermiyahu, U., Alexandrov, B., Rasmussen, K. $\varnothing$., et al. (2020). Increased irrigation water salinity enhances nitrate transport to deep unsaturated soil. Vadose Zo. J. 19, 1-16. doi: 10.1002/vzj2.20041

Yihdego, Y., and Al-Weshah, R. (2018). Treatment of worlds largest and extensively hydrocarbon polluted environment: Experimental approach and feasibility analysis. Int. J. Hydrol. Sci. Technol. 8, 190-208. doi: 10.1504/IJHST.2018.090897

Yihdego, Y., Danis, C., and Paffard, A. (2017). Why is the Groundwater Level Rising? A case study using HARTT to simulate groundwater level dynamic. Water Environ. Res. 89, 2142-2152. doi: 10.2175/106143017X14839994523785

Conflict of Interest: The author declares that the research was conducted in the absence of any commercial or financial relationships that could be construed as a potential conflict of interest.

Copyright (C) 2020 Dahan. This is an open-access article distributed under the terms of the Creative Commons Attribution License (CC BY). The use, distribution or reproduction in other forums is permitted, provided the original author(s) and the copyright owner(s) are credited and that the original publication in this journal is cited, in accordance with accepted academic practice. No use, distribution or reproduction is permitted which does not comply with these terms. 